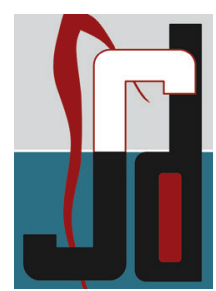

CASE SERIES

\title{
Management OfCapillary Hemangioma In The Oral Cavity Of A Pregnant Patient: A Rare Case Report
}

Veena Raj VasanthaKumari ${ }^{1}$, Sabari Chandra Mohan ${ }^{2}$, Seema Geetha ${ }^{3}$,

ABSTRACT : Hemangiomas are benign tumors composed of blood vessels. Capillary hemangiomas are developmental hamartomatous lesions of the vascular tissue, which are common in infancy and adolescents. Head and neck are the most prevalent sites for origin of hemangiomas, but are rarely observed in the oral cavity. This paper presents a rare case report of capillary hemangioma on the palate of a pregnant patient, which was managed by laser therapy with satisfactory uneventful healing. The characteristic clinical and histo-pathologic features of vascular tumors and malformations, especially capillary hemangiomas are discussed.

Keywords: Capillary hemangioma, Pregnant, Laser

\section{Introduction}

Hemangiomas are benign tumors composed of blood vessels. Based on their histological appearance, they are classified as capillary, mixed cavernous, or a sclerosing variety that tends to undergo fibrosis. It is the most common benign tumor of the head and neck region especially in children, but it rarely occurs in the oral cavity. Although, it is considered as one of the common soft-tissue tumors of the head and neck, it is relatively rare in the oral cavity. Capillary hemangiomas are composed of many small capillaries lined with a single layer of endothelial cells supported in a connective tissue stroma of varying density. ${ }^{2}$ Previous studies show that it has a higher incidence rate in females and usually occurs in the lips,cheeks and tongue. ${ }^{3}$

\section{Case Report}

A 20 year old pregnant female patient reported with a painful swelling with bleeding in the palatal area of upper left back teeth (Figure 1). The swelling was noticed 3 months back, which gradually increased in size, with a history of frequent bleeding while eating and swallowing. Frequency of bleeding had increased since 1 week. Patient was in her fourth month of pregnancy without any other relevant medical history.

On intra-oral examination, a $2 \mathrm{~cm} \times 2 \mathrm{~cm}$ sized solitary,sessile,rhomboid shaped, reddish pink swelling with distinct borders and irregular surface was seen on the palatal aspect of 25 and 26 (Figure
$3 \& 4)$. The surrounding palatal mucosa was normal. On palpation, the swelling was non-tender, soft to firm in consistency and blanched on pressure. Intra-oral hard tissue examination and radiographs were normal (Figure 2). Pre-operative hematological examination revealed all readings within normal parameters. Based on the clinical appearance of the lesion and history, a provisional diagnosis of pyogenic granuloma was made. The differential diagnosis included hemangioma, fibroma and peripheral giant cell granuloma.

After obtaining a written informed consent from the patient, supragingival scaling and patient education was done regarding good oral hygiene maintenance. After 1 week, laser excision of the growth was done under local anesthesia (Figure 5). The excised tissue (Figure 6) was fixed in 10\% neutral buffered formalin and was sent for routine histopathological examination. Post-operative bleeding was arrested by laser banding of the excised area (Figure 7). Periodontal dressings were placed in the excised area and post-operative instructions and analgesics were given (Figure 8). Patient was recalled after 1 week, periodontal dressings were removed (Figure 9). The healing was uneventful and satisfactory.Patient was kept in maintenance phase with a periodic recall of every 6 month and no reccurence was reported (Figure 10).

Histopathologically, the excised specimen showed mucosa lined by parakeratotic squamous epithelium with underlying subepithelium showing proliferated 
small and medium sized blood vessels lined by endothelium(Figure $11 \& 12$ ). The stroma shows fibrous tissue and inflammation. Correlating the microscopic features with the clinical picture,histopathological examination confirmed the diagnosis as "Capillary hemangioma".

\section{Discussion}

Hemangiomas are common benign tumors of the head and neck region but their occurrence on the palatal mucosa is extremely rare. ${ }^{4}$ In $80 \%$ of cases, hemangiomas occur as single lesions. Histologically they are classified into capillary and cavernous types. ${ }^{5}$ Hemangiomas are considered to be benign tumors of infancy, characterized by a rapid growth phase with endothelial cell proliferation followed by gradual involution. ${ }^{6}$ They constitute $7 \%$ of all benign tumors in infancy and childhood that present rarely in the oral cavity. In addition, confusion with other conditions can occur since hemangiomas may mimic other lesions clinically, radiographically and at times histologically. Capillary Hemangiomas $(\mathrm{CH})$ are most often recognized at an early age with female predilection (ratio of 3:1) in second and third decades of life. ${ }^{7}$ Clinically, hemangiomas of the oral soft tissues appears as a painless, soft, smooth or lobulated, sessile or pedunculated mass and may be seen in any size from a few millimeters to several centimeters. ${ }^{8}$ The development of these lesions are usually slow with deep red or bluish red in colour. Periodontally these lesions often appear to arise from the interdental papilla and spread laterally to involve adjacent teeth which is usually painless.

Vascular anomalies of head and neck historically have confused clinicians which have resulted in difficult study, improper diagnosis, and inappropriate treatment. The differentialdiagnosis of hemangiomas includes pyogenicgranuloma, peripheral giant cell granuloma, peripheralossifying fibroma, chronic inflammatory gingivalhyperplasia (epulis) and squamous cell carcinoma. ${ }^{9}$ The classification of hemangiomas is based on histologicalappearance; therefore histopathological assessment remains the most accurate and satisfactory means ofdiagnosis. Since capillary hemangioma and pyogenic granuloma exhibit similar clinical features, biopsy of the lesion is mandatory for definitive diagnosis and to rule out more seriousconditions.
The management ofhemangiomas of the oralmucosa varies according to the various factors likethe age of the patient, thesize of the lesion, the site of involvement and theclinical nature of the hemangioma. ${ }^{10}$ The most common treatment of choice for hemangioma is surgical excisionof the lesionwithor without ligation of vessels and embolization. ${ }^{11}$ Recently other treatment modalities are also developed which includes steroid therapy, electrosurgery, Nd: YAG laser, $\mathrm{CO}_{2}$ laser, diode laser, cryosurgery and use of sclerosing agents. ${ }^{12}$ Surgical management shouldbe executed with caution taking into consideration the possibility of bleeding intraoperatively and post-operatively.

The present case in the discussion is significant because of its uncommon location in the palate of a pregnant patient. Radiographs are advised to rule out bony destruction which is suggestive of central variety of hemangioma,malignancy and to identify the presence of any other foreign body which has to be removed along with the lesion.In the present case, laser excision was preferredas the patient was pregnant and the lesion was large and it bled on palpation.Laser excision of the lesion seems to be a safe and noninvasive methodwhereby a pregnant patient canbe managed without any complications. The healing was uneventful and satisfactory. The patient responded well to the treatment, and was kept on maintenance visits for 1 year. No recurrence has been reported till date.

\section{Conclusion}

Capillary hemangioma is a lesion that is diagnosed primarily on histological findings. Although, it is asymptomatic, its peculiar location may require immediate intervention. The case in the discussion was worthy of importance because of its uncommon location on palateof a pregnant patient. Lesions in this area often lead to impaired nutrition and oral hygiene, increased accumulation of plaque and microorganisms and thereby increased susceptibility to oral infections. The clinical picture and location of the lesion led to a provisional diagnosis of pyogenic granuloma, but histological findings were suggestive of capillary hemangioma. Early detection and biopsy of such lesions is necessary to institute appropriate management. In addition, the surgical management should be performed with caution because the tissues may bleed profusely intra-operatively and post-operatively. 


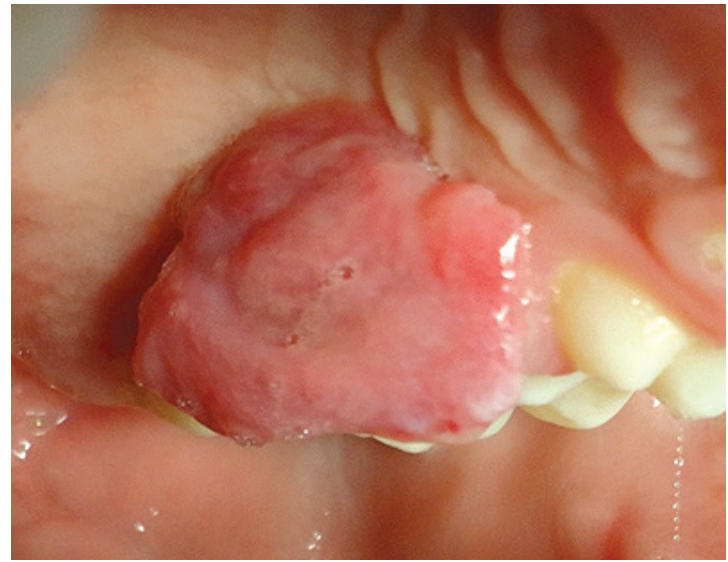

Figure 1. Pre-operative view

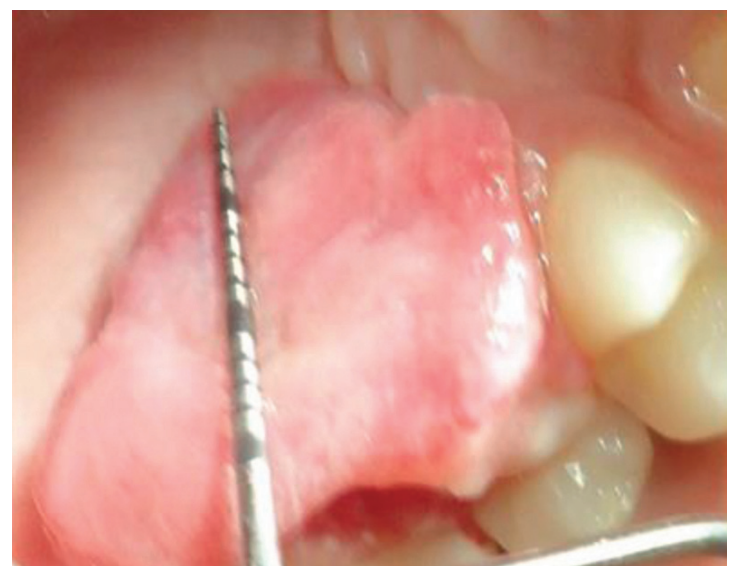

Figure 3. Pre -operative measurements

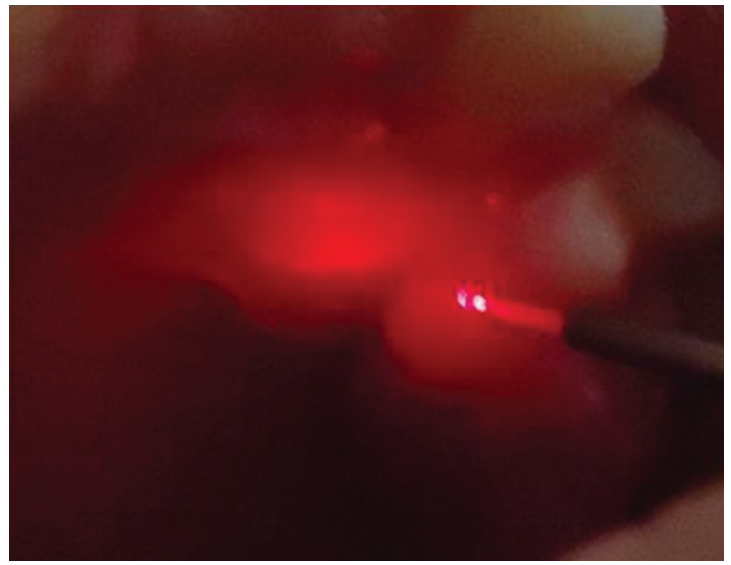

Figure 5. Laser excision of the lesion

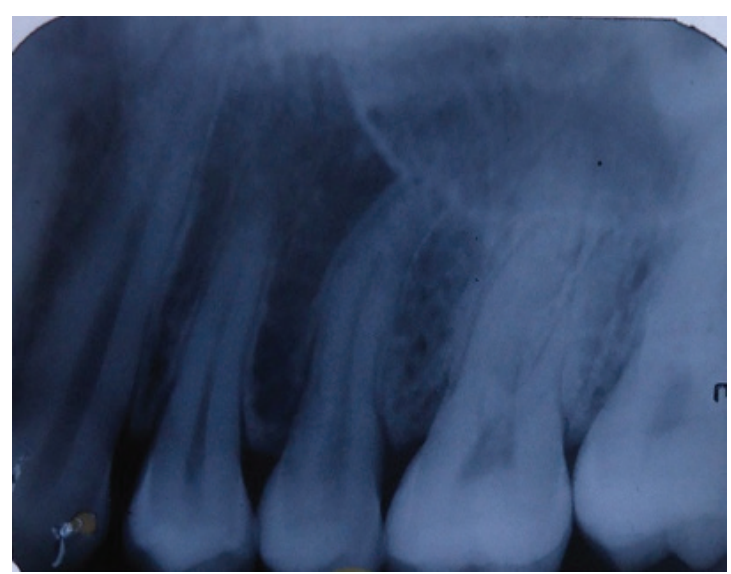

Figure 2. Pre-operative IOPAR of the site

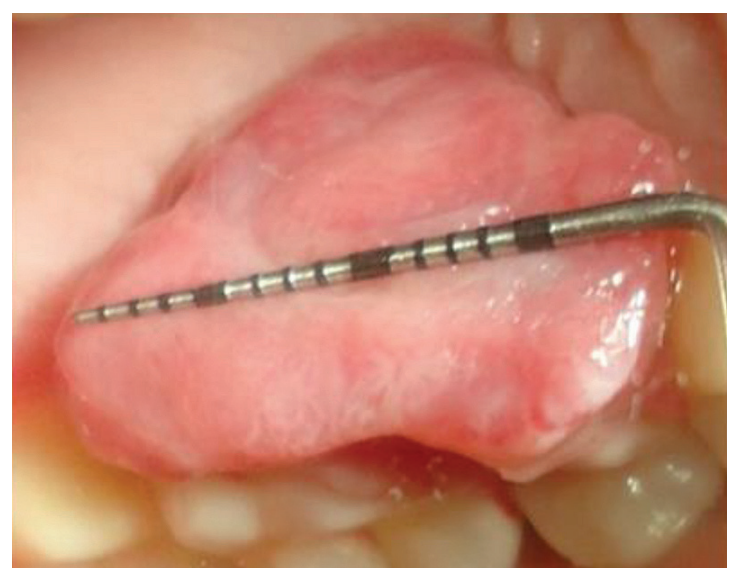

Figure 4. Pre -operative measurements



Figure 6. Excised tissue 


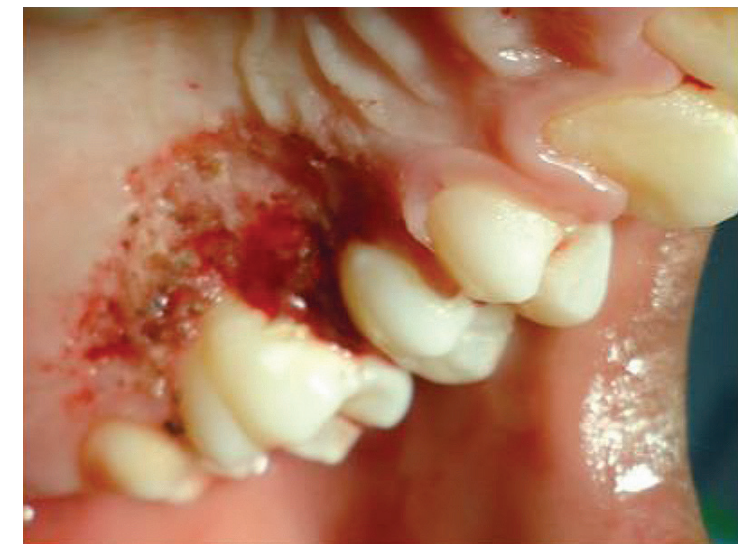

Figure 7. After excision and laser banding

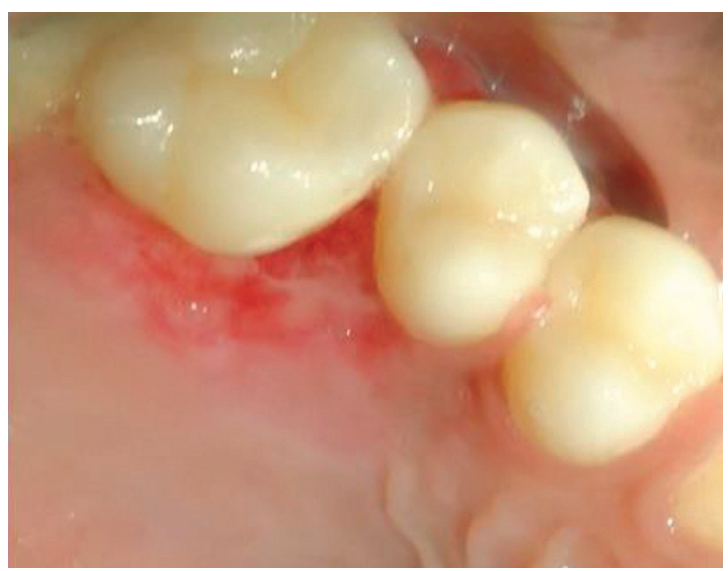

Figure 9. Post-operative view after 1 week

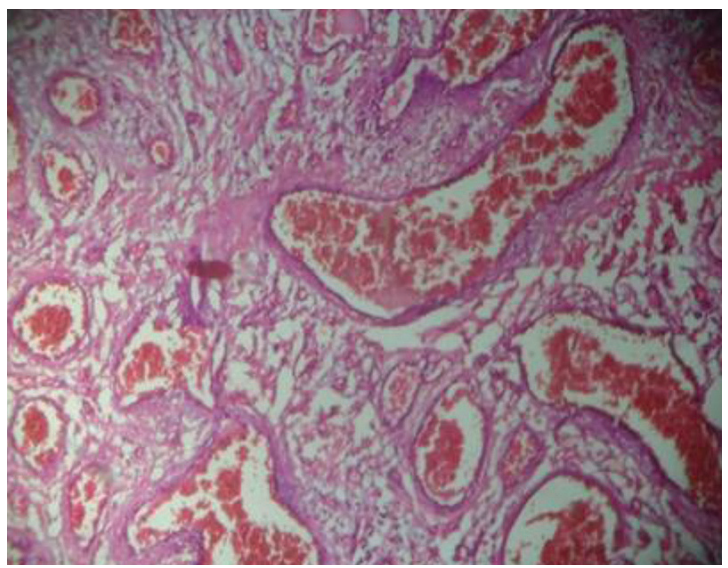

Figure 11. H\&E stain low power magnification $\mathbf{x 1 0 x}$

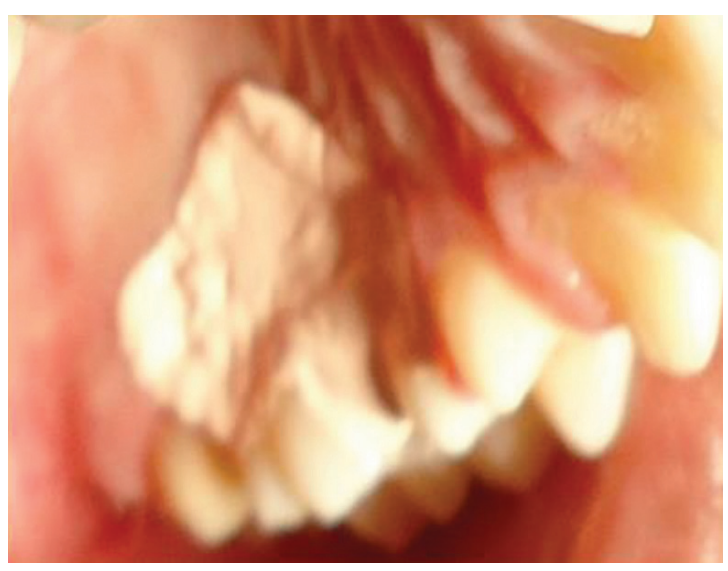

Figure 8. Coe - pack placed in the site

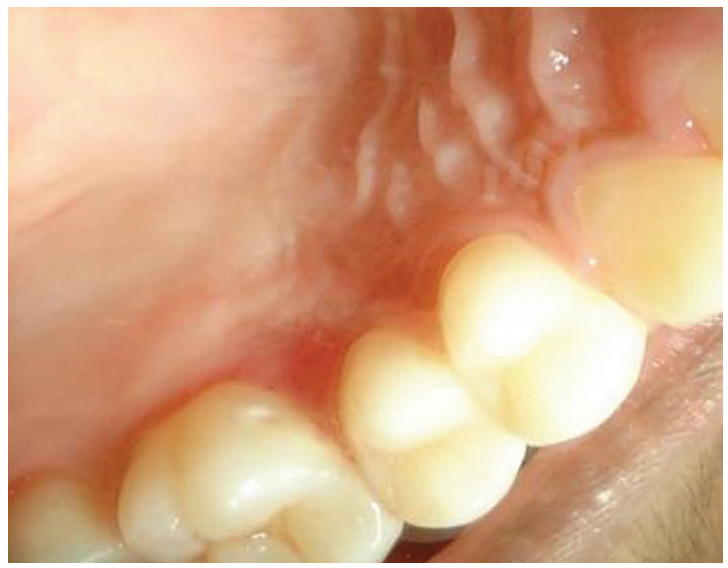

Figure 10. Post-operative view after 6 months

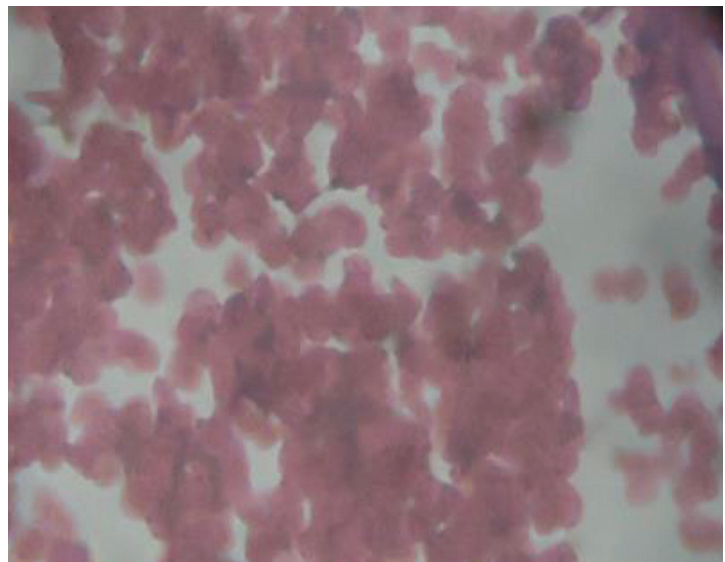

Figure 12. H\&E stain high power magnification $\times 40 x$ 
Dental surgeons should be aware of the risks while managing these innocent lesions and should take necessary precautions prior to attempts at excision of these lesions as it often mimics other lesions clinically and require appropriate clinical diagnosis and proper management. Early detection and biopsy is necessary to determine the clinical behaviour and potential dentoalveolar complications

\section{Acknowledgement}

The corresponding author thanks all the faculties and post graduate students of Department of Periodontics, Sri Sankara Dental College, Varkala, Trivandrum for their valuable support for successful completion of this work.

\section{Source of support : Nil}

The authors report no conflicts of interest related to this work.

\section{REFERENCES}

1. Açikgöz A, Sakallioglu U, Ozdamar S, Uysal A. Rare benign tumours of oral cavity - Capillary haemangioma of palatal mucosa: A case report. Int J Paediatr Dent 2000;10:161-5.

2. Jananni M, Gubernath U, Mahendra J, Sivaramakrishnan M. Capillary hemangioma of gingiva mimicking as pyogenic granuloma: Report of two cases. J Interdiscip Dent 2012;2:218-20.

3. Mulliken JB. Cutaneous Vascular Anomalies. In: Mccarthy JG Editor. Plastic Surgery: Tumors of Head and Neck and Skin. Vol 5. Philadelphia: B Saunders Company Ltd.: 1990. p. 3194230 .

4. Schoen FJ. Vessels B. In: Kumar V, Abbas AK, Fausto N, editors. Robbins and Cotran: Pathological basis of disease. 7th ed, Philadelphia: Saunders; 2004. P. 511-54.
5. Mills SE, Cooper PH, Fechner RE. Lobular capillary hemangioma: The underlying [1] lesion of pyogenic granuloma. A study of 73 cases from the oral and nasal mucous membrane. Am J SurgPatho. 1980;4:470-79.

6. Neville BW, Damm DD, Allen CM, Bouquot JE. Oral \& Maxillofacial Pathology. [4] Saunders Philadelphia, 2nd edition, 2002;390-92.

7. Bayrak S, Dalci K, Tansel H. Capillary hemangioma of the palatal mucosa: Report [2] of an unusual case. SÜ DishekFakDerg. 2010;19:87-89.

8. Dahlin DC, Unni KK. Bone tumours: General aspects and data on 542 cases. [6] Springfield III. 1986;14:3-17.

9. Wood NK, Goaz PW. Differential diagnosis of oral and maxillofacial regions, [11] Mosby, 5th edition; 1997, 549-50.

10. Rachappa MM, Triveni MN. Capillary hemangioma or pyogenic granuloma: A [12] diagnostic dialemma. Contemporary clinical dentistry. 2010;12:119-22.

11. Handa R, Sheikh S, Shambulingappa P, Aggarwal A, Mago J, Salaria S. [14] Capillary hemangioma of palate: A case report. Pakistan Oral \& Dental Journal. 2013;33(1):55-57.

12. Matsumoto N, Tsuchiya M, Nomoto S, Matsue $Y$, Nishikawa Y, Takamura T, et al. [8] CD105 expression in oral capillary hemangiomas and cavernous hemangiomas. Journal of Oral Science. 2015;57:45-53. 


\section{Address of Correspondence}

Dr. Veena Raj V.

Ravi Bhavan, Vembayam P.O

Trivandrum, Kerala - 695615

e-mail: veenarajv1@gmail.com

Contact no: 9495638414

\section{Authors:}

${ }^{1}$ Post Graduate Student, Department of Periodontics, Sri Sankara

Dental College, Varkala, Trivandrum, Kerala

${ }^{2}$ Reader, Department of Periodontics, Sri Sankara Dental College, Varkala, Trivandrum, Kerala

${ }^{3}$ Professor and Head, Department of Periodontics, Sri Sankara Dental College, Varkala, Trivandrum, Kerala

\section{How to cite this article :}

Veena Raj VasanthaKumari, Sabari Chandra Mohan, Seema Geetha. Management OfCapillary Hemangioma In The Oral Cavity Of A Pregnant Patient: A Rare Case Report. Journal of Scientific Dentistry, 2016;6(2):40-45

Source of Support : Nil, Conflicts of Interest : None declared 